\title{
PERSONAL EFFECTIVENESS OF PUBLIC HEALTH MANAGEMENT PERSONNEL IN SOUTH EAST ASIA REGION: A STUDY
}

\author{
Jain NP', Md Shahnawaz ${ }^{2}$, Gupta SD², Jha RK ${ }^{4}$, Bhatta GK \\ 1, 2, 3, Institute of Health Management Research, IHMR, Jaipur, Rajasthan, India \\ ${ }^{4}$ Kathmandu, Nepal \\ ${ }^{5}$ SAARC TB and HIVIAIDS Centre, Kathmandu, Nepal
}

\begin{abstract}
Introduction: Personal Effectiveness is being the best to oneself by mobilizing motivation and galvanizing cognitive capability in order to address the demand of a given situation. The objectives of the study were: i) to calculate the personal effectiveness scores under the three categories: self-disclosure, openness to feedback, and perceptiveness, ii) to determine the type of personal effectiveness and which dimension of personal effectiveness is lacking among the health personnel mostly. ii) to develop personal effectiveness norms for public health management personnel in South East Asia region under the categories of self-disclosure, openness to feedback and perceptiveness.
\end{abstract}

Methodology: Personal Effectiveness (PE) scale developed by Prof Udai Pareek was administered on 74 public health management personnel, who attended various leadership and management training programmes during 2009-2012, in South East Asia Region (SEAR). Using 10 as "cut-off" for high or low scores, combining the three dimensions of personal effectiveness the respondents were categorized in to eight categories, ranging from effective to ineffective.

Results: More than three-fourths of the public health management personnel in SEAR were found to be 'high' on openness to receiving feedback followed by three-fifths who have 'high' perceptiveness. However, less than one-half have 'high' self-disclosure. The compositions of the three dimensions of personal effectiveness of all the respondents suggested that about one-fourth were 'effective'. Nearly one-third of the respondents were found to be 'secretive". One out of every ten respondents was found to be "ineffective".

Conclusion: The public health management personnel need to work upon enhancing their personal effectiveness by sharing and becoming sensitive to others.

Key words: Health Management Personnel, Norms, Personal Effectiveness, South East Asia Region

\section{INTRODUCTION}

Senior managers of health care programs around the world have been expressing the urgent need to professionalize the leadership and management of health care services. ${ }^{1}$ It is also true that if we want to change others, first we need to change

\footnotetext{
Correspondence:

Dr. Jain Nutan Prabha

Professor

Institute of Health Management Research, IHMR

1 Prabhu Dayal Marg, Jaipur 302011, Rajasthan, India

Email - nutan@iihmr.org
}

ourselves. Since the core of change is the self, and understanding about the self (oneself). ${ }^{2}$

Personal Effectiveness is about unlocking the potential that an individual possess. While personality measurement helps us to see a consistent pattern in a person's orientation, individuals with different types of personalities can be equally effective. Personal effectiveness refers to beliefs in one's capacities to derive motivation, cognitive resources and courses of action to meet given situational demands. One precondition for personal effectiveness is better self-awareness. But only understanding oneself does not make a 
person effective. It assesses the consistency in an individual's orientation towards the situation. Different personality types can be equally effective depending on how well s/he knowing oneself and managing the responses of those with whom $\mathrm{s} /$ he interacts. Openness is critical for personal effectiveness. It has two aspects-self-disclosure (sharing with others what they do not seem to know about one- self) and use of feedback (being open to what others say on aspects which one may not be aware of). In addition, perceptiveness or sensitivity to others' feelings and to non-verbal cues is also important. $^{3}$

The Johari Window ${ }^{4}$ model developed by Luft and Ingham [Fig 1] is helpful in understanding two main dimensions of self: those aspects of a person's behavior and response type that are known to him/her (self) and those aspects of his/ her behavior that are known to those with whom s/ he interacts (others). PE used to help people better understands their relationship with self and others, in the blind and the closed areas.

Arena (A): Part of an individual's behavior known both to him/herself and to those with whom the individual interacts. This area of Arena (Fig.1) includes information regarding name, age, family, appearance and organization.

Blind $(B)$ : The blind area suggests those aspects of the personal behavior of an individual known to others, but the person him/herself does not know. A person may behave in a certain way in a situation that is not known to him/her but may be annoying, pleasing or funny.

Closed (C): This involves which is known to the person but not expressed to others. There are many situations when an individual do not wish to reveal his/her feelings.

Dark (D): This area is termed as dark as it is inaccessible to both self and others. This can't be consciously controlled.

In this model, the size of the arena is crucial for $P E$. This area increases in size to the proportion of decrease.

In this backdrop, this paper is an attempt to further discuss the issue under three specific objectives: i) to calculate the personal effectiveness scores under the three categories: self-disclosure, openness to feedback, and perceptiveness, ii) to know the type of personal effectiveness and which dimension of personal effectiveness is lacking among the health personnel mostly. ii) to develop PE norms for public health management personnel in South East Asia region under the categories of self-disclosure, openness to feedback and perceptiveness.

\section{METHODOLOGY}

Personal Effectiveness scale, developed by Prof Udai Pareek ${ }^{1}$, was administered on 74 public health management personnel, who attended various leadership and management training programmes during 2009-2012, in South East Asia Region (SEAR). The scale contains 15 statements, five for each of the three dimensions. The reliability of the scale was 0.90 (Pareek 2010). The respondent read the each statement, indicating the extent to which it is true of him/her on a five-point likert scale. The range of scores for each dimension to an individual could be between 0 and 20. The responses were categorized into 10 or less than 10 (considered as 'low') and above 10 (considered as 'high') as suggested by Prof Pareek. Further to it based on high or low scores, combining the three dimensions of personal effectiveness i.e. self-disclosure, openness to feedback and perceptiveness, the respondents were categorized in to eight categories, ranging from effective to ineffective. The eight categories are explained in table 1.

Microsoft Excel (MS 2007) and Statistical Package for Social Sciences (SPSS version 16) have been used for analysis. Mean and Standard Deviation (SD) with normal curve of self-disclosure, openness to feedback and perceptiveness were taken into account in order to know the mean norms range of each category with 95 percent Confidence Interval (Cl).

\section{RESULTS}

The results revealed that more than three-fourths $(82 \%)$ of the public health management personnel in SEAR were found to be 'high' on openness to receiving feedback followed by $61 \%$ who have 'high' perceptiveness. However, less than one-half (46\%) have 'high' self-disclosure (figure 2).

The compositions of the three dimensions of personal effectiveness of all the 74 respondents 
suggested that about one-fourth $(26 \%)$ of the public health management personnel of SEAR were 'effective'. Nearly one-third (31\%) of the respondents were found to be 'secretive which means with low self-disclosure followed by insensitive i.e. low on perceptiveness (13\%), task-obsessed i.e. low on both self-disclosure and perceptiveness $(12 \%)$. Nearly one out of every ten public health managers was found "ineffective" that is low on all the three dimensions (figure 3). Therefore, it is evident that "self-disclosure" and "perceptiveness" are two dimensions where the public health personnel need to focus upon.

To understand the variations among "high" scores for various PE types, average scores were calculated for the each dimension (table 2). There was no wide variation was observed among "high" average scores of "self-disclosure" except dogmatic type. However, the highest average scores were found to be for effective type. Similarly, all the high scores on openness to feedback were in the range of 14 to 15.9, highest for "effective" and lowest for "insensitive" type.

Among the high scores on perceptiveness, a wide variation could be seen between effective and dogmatic type. However, numbers are too less for dogmatic type to conclude (table 2).

The norms of the personal effectiveness were calculated for 68 managers by Prof Pareek (table 3 ) in 2002. However, it was felt necessary to calculate the norms for health personnel in South East Asia region.

\section{Norms for Self-disclosure}

The mean score for self-disclosure of 74 SEAR health personnel was found to be 10.54 with standard deviation (SD) is \pm 3.421 (figure 4 ). The mean score falls between 9.76 and 11.32 with 95 percent Confidence Interval $(\mathrm{Cl})$.

\section{Norms for openness to feedback}

The mean score of self-disclosure of the public health personnel was found to be 13.8 with standard deviation (SD) \pm 3.37 (figure 5). The mean score falls between 13.03 and 14.56 with 95 percent Confidence Interval $(\mathrm{Cl})$.

\section{Perceptiveness}

The mean score on perceptiveness of the SEAR health personnel was 11.85 along with standard deviation (SD) \pm 3.43 (figure 6). The mean score falls between 11.06 and 12.63 with 95 percent Confidence Interval $(\mathrm{Cl})$.

\begin{tabular}{|c|l|c|c|c|}
\hline \multicolumn{4}{|l|}{ Table 1. Types of personal effectiveness } \\
\hline \multicolumn{2}{|l|}{ Category } & $\begin{array}{c}\text { Self- } \\
\text { disclosure }\end{array}$ & $\begin{array}{c}\text { Openness } \\
\text { to feedback }\end{array}$ & Perceptiveness \\
\hline 1 & Effective & High & High & High \\
\hline 2 & Insensitive & High & High & Low \\
\hline 3 & Egocentric & High & Low & Low \\
\hline 4 & Dogmatic & High & Low & High \\
\hline 5 & Secretive & Low & High & High \\
\hline 6 & $\begin{array}{l}\text { Task- } \\
\text { obsessed }\end{array}$ & Low & High & Low \\
\hline 7 & $\begin{array}{l}\text { Lonely } \\
\text { Empathic }\end{array}$ & Low & Low & High \\
\hline 8 & Ineffective & Low & Low & Low \\
\hline
\end{tabular}

Table 2. Percent distribution of the respondents by their type of personal effectiveness $(n=74)$ and mean score of each group on three dimensions

\begin{tabular}{|c|c|c|c|c|}
\hline Category & $\%$ & \begin{tabular}{|c|} 
Self- \\
disclosure \\
(Average)
\end{tabular} & $\begin{array}{c}\text { Openness } \\
\text { to } \\
\text { feedback } \\
\text { (Average) }\end{array}$ & $\begin{array}{c}\text { Perceptiveness } \\
\text { (Average) }\end{array}$ \\
\hline \begin{tabular}{|l|} 
Effective \\
$(n=19)$
\end{tabular} & 26 & High (13.8) & $\begin{array}{l}\text { High } \\
(15.9)\end{array}$ & $\begin{array}{c}\text { High } \\
(15.1)\end{array}$ \\
\hline \begin{tabular}{|l|} 
Insensitive \\
$(n=10)$
\end{tabular} & 13 & High (13.4) & $\begin{array}{l}\text { High } \\
(14.0)\end{array}$ & $\begin{array}{l}\text { Low } \\
(8.0)\end{array}$ \\
\hline $\begin{array}{l}\text { Egocentric } \\
(n=2)\end{array}$ & 3 & High (13.0) & $\begin{array}{l}\text { Low } \\
(10.0)\end{array}$ & $\begin{array}{l}\text { Low } \\
(8.0)\end{array}$ \\
\hline $\begin{array}{l}\text { Dogmatic } \\
(\mathrm{n}=3)\end{array}$ & 4 & High (12.3) & $\begin{array}{l}\text { Low } \\
(6.6) \\
\end{array}$ & $\begin{array}{l}\text { High } \\
(12.3)\end{array}$ \\
\hline $\begin{array}{l}\text { Secretive } \\
(\mathrm{n}=23)\end{array}$ & 31 & $\begin{array}{l}\text { Low } \\
(8.4)\end{array}$ & $\begin{array}{c}\text { High } \\
(14.5)\end{array}$ & $\begin{array}{c}\text { High } \\
(13.4)\end{array}$ \\
\hline \begin{tabular}{|l|} 
Task- \\
obsessed \\
$(n=9)$
\end{tabular} & 12 & $\begin{array}{l}\text { Low } \\
(7.6)\end{array}$ & $\begin{array}{l}\text { High } \\
(14.6)\end{array}$ & $\begin{array}{l}\text { Low } \\
(9.2)\end{array}$ \\
\hline \begin{tabular}{|l|} 
Lonely \\
Empathic \\
$(\mathrm{n}=0)$ \\
\end{tabular} & 0 & $\begin{array}{l}\text { Low } \\
(0.0)\end{array}$ & $\begin{array}{l}\text { Low } \\
(0.0)\end{array}$ & $\begin{array}{l}\text { High } \\
(0)\end{array}$ \\
\hline \begin{tabular}{|l|} 
Ineffective \\
$(n=8)$
\end{tabular} & 11 & $\begin{array}{l}\text { Low } \\
(7.1) \\
\end{array}$ & $\begin{array}{l}\text { Low } \\
(9.0) \\
\end{array}$ & $\begin{array}{l}\text { Low } \\
(8.12) \\
\end{array}$ \\
\hline Total (74) & 100 & & & \\
\hline
\end{tabular}

Table 3. Norms for PE dimensions

\begin{tabular}{|l|c|c|c|c|c|}
\hline \multirow{2}{*}{ Variable } & \multicolumn{2}{|c|}{$\begin{array}{c}\text { Norms calculated as per the } \\
\text { SEAR data }(\mathbf{n = 7 4 )}\end{array}$} & \multicolumn{2}{|c|}{$\begin{array}{c}\text { Norms by } \\
\text { Prof. Udai } \\
\text { Pareek ( } \mathbf{n}=68)\end{array}$} \\
\cline { 2 - 6 } & Mean & $S D$ & $\begin{array}{c}\text { Norms } \\
\text { Range (with } \\
95 \% \text { Cl) }\end{array}$ & Mean & $S D$ \\
\hline Self-disclosure & 10.54 & \pm 3.42 & 9.76 to 11.32 & 10 & 3 \\
\hline $\begin{array}{l}\text { Openness to } \\
\text { feedback }\end{array}$ & 13.80 & \pm 3.37 & $\begin{array}{c}13 \text { to } \\
14.56\end{array}$ & 14 & 3 \\
\hline Perceptiveness & 11.85 & \pm 3.43 & $\begin{array}{c}11 \text { to } \\
12.63\end{array}$ & 13 & 3 \\
\hline
\end{tabular}




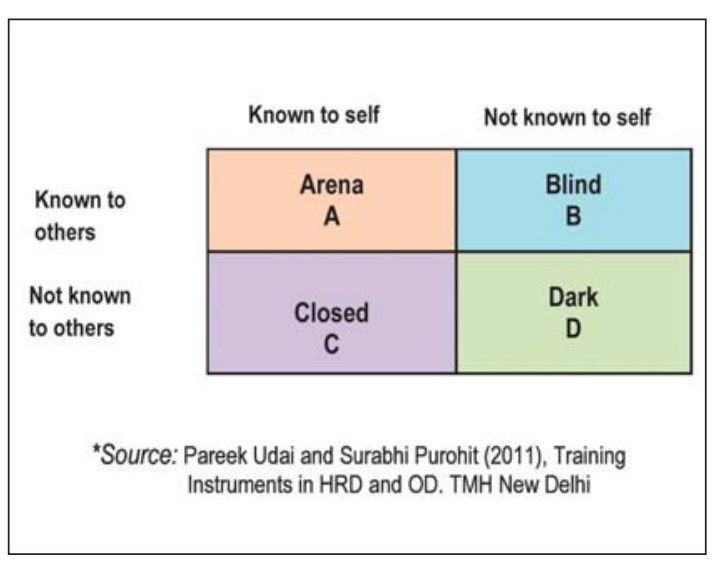

Figure 1. Johari Window* (Joseph Luft, Harrington Ingham, 1955)

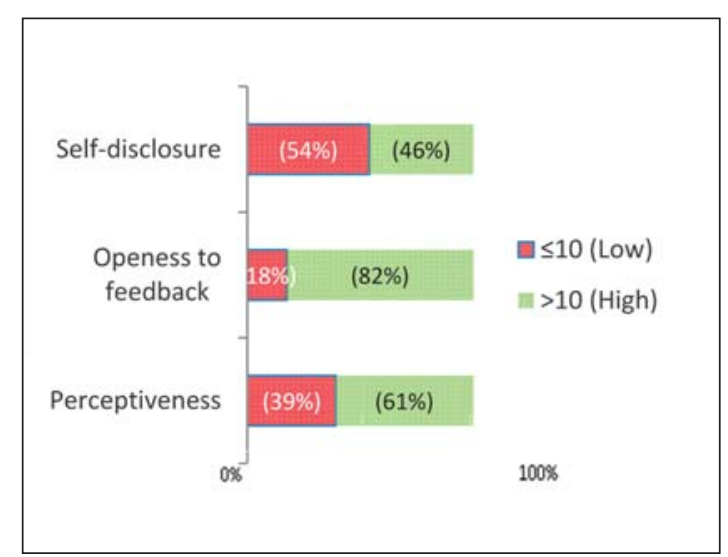

Figure 2. Distribution of the respondents by their scores: $>10$ and $<10$ on three dimensions of personal effectiveness

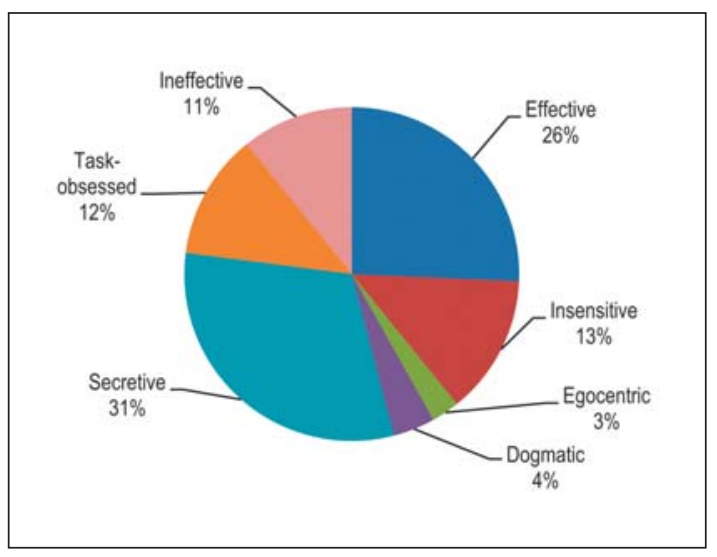

Figure 3. Percent distribution of the respondents by their PE type

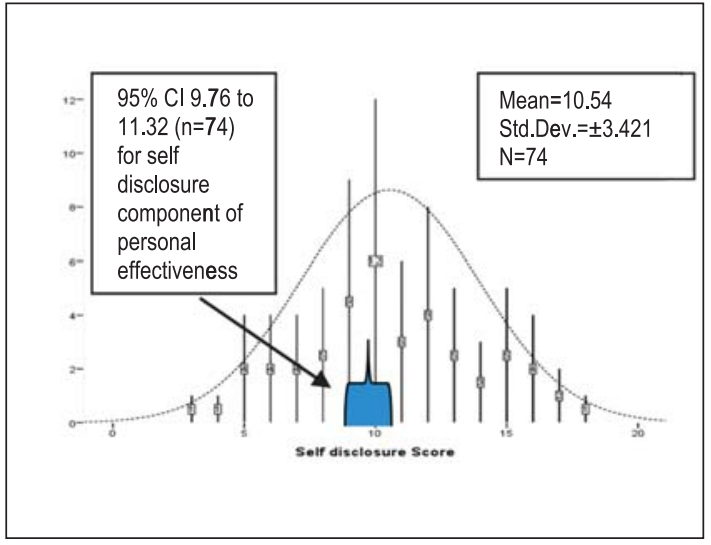

Figure 4. Scores on Self-disclosure plotted on normal probability curve

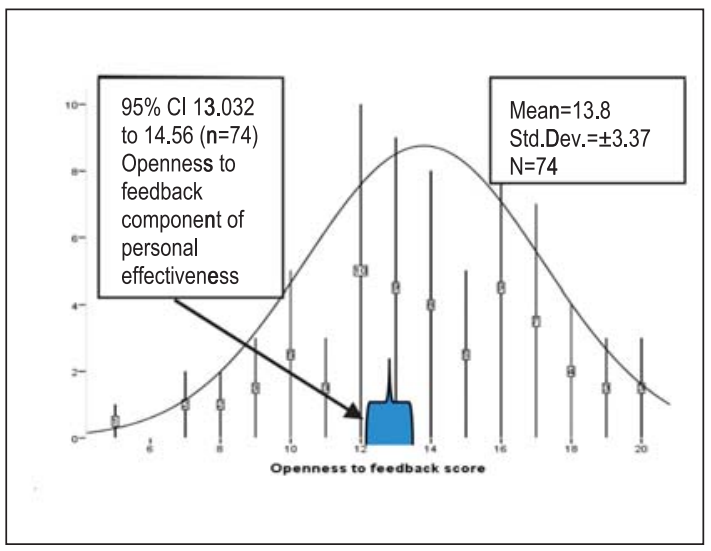

Figure 5. Scores on openness to feedback plotted on normal probability curve

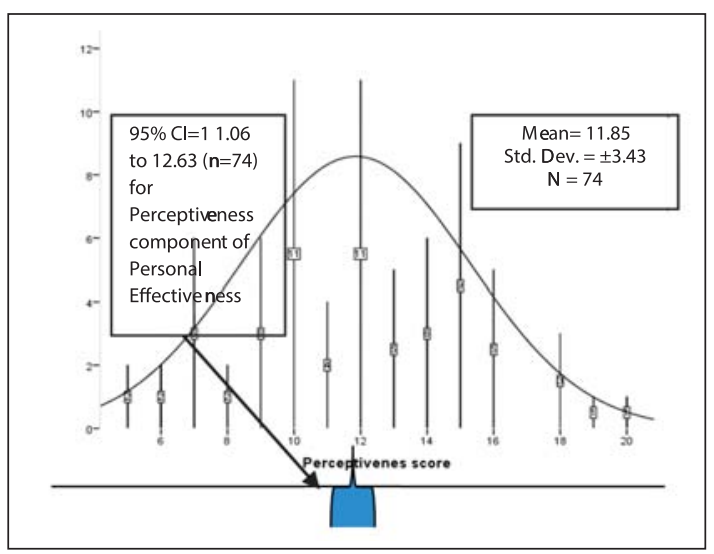

Figure 6. Scores on perceptiveness plotted on normal probability curve 


\section{DISCUSSION}

Out of three dimensions of personal effectiveness, two aspects i.e. self-disclosure and perceptiveness need attention to health management personnel. If the respondents who were found to be low on self disclosure and categorized as "secretive' could work on expressing their feelings to others and become effective. Usually, Secretive type of people find it difficult to be frank with people unless they know them well. They need to enhance their "Arena" for their personal effectiveness by sharing what they want to share is appropriate with others. The extent to which one shares ideas, feelings, experiences, impressions, perceptions appropriately shows the degree of openness. Analysis shows that almost one-third of the SEAR health personnel were found to be 'Secretive' and they were lagging behind only in 'self disclosure' component of personal effectiveness. Self-disclosure is sometimes misunderstood as disclosing everything about oneself with everyone. Self-disclosure is important achieving goals, such as developing relationship, closeness, gaining emotional support, etc. Effectiveness of self-disclosure depends on how much does the disclosure, as a communication act, accomplish the discloser's as well as the listener's goals. ${ }^{6,7}$ With sustained training and practices on sharing of appropriate and relevant ideas, opinions and feelings related to works leads to mutual trust and thus enhance personal effectiveness. ${ }^{5}$

The other group that raises concern with respect to this study is of 'Insensitive'. Thirteen percent health management personnel under this study group have shown low perceptiveness. They used to say things that turn out of place, fail to pick up cues about others' feelings and reactions when involved in an argument or a conversation thereby they were being found to be 'low' in perceptiveness. Combining perceptiveness with the other two dimensions i.e. self-disclosure and openness to feedback, a person who is not open may receive many cues and much feedback from others. Perceptiveness and openness reinforce each other for personal effectiveness. Perceptiveness can be improved by learning and practice like checking with others about their reactions to what has been said, working on one's listening skills, being aware of language, gestures and facial expressions ${ }^{5}$. This allows people to develop trust and respect that ultimately lead to better service delivery.
In general, people hear criticism at that time but do not bother about it later. Feedback on those aspects of a person about which others are aware but the person him/herself does not know about may be positive or negative. Negative feedback creates dissonance with self-image, and the person tends to be defensive, and generally uses defensive behavior (for example, denial, rationalization, aggression, etc.) to deal with the feedback. However, the main purpose of feedback is to develop mutuality, trust and openness, the more defensive behavior is used, the less effective it will be. The individual receiving feedback need to examine his/ her defensive behavior and prepare to plan (preferable with the help of one or more persons) for reducing it. By being open to receiving feedback, we could reduce our blind area and increasing up Arena. Feedback may be given to others to improve the situation and to reduce their blind areas. We should recognize valid points even if we don't agree with the other person's interpretation. Developmental and motivational feedbacks are considered as inevitable aspect of effective performance.

The findings are the same that reflects reliability of the results. A summary of norms calculated for South East Asia region is presented and compared with the norms by Prof Pareek in table 3. It is withstanding to note that there was no difference in these two variables namely "self-disclosure" and "openness to feedback" calculated at different points of time (Prof Pareek in 2002 and the data is used in the study was drawn during year 20092012). On the "perceptiveness" dimension there was difference of 1.15 in the mean scores as Prof Pareek has mentioned "13" and the study norms calculated as 11.85. However, the standard deviations were remained almost same.

This study shed light on the norms of health management personnel in this part of the region where the public health situation is in demanding need. The norms can be used for the purpose of reference, research and training in the public health domain.

All the leadership and management development programs need to incorporate personal effectiveness in the contents to start the change within. It will help the person to understand him/ herself which will further give a scope to understand others in a better way. 


\section{REFERENCES}

1 Management Sciences for Health (MSH), "An Urgent Call to Professionalize Leadership and Management in Health Care Worldwide," Occasional Paper No. 4. Cambridge, MA: MSH, 2006

2 Udai Pareek, Surabhi Purohit. Training Instruments in HRD and OD. New Delhi: Tata McGraw-Hill; 2011

3 Udai Pareek, Revised and updated by Sushama Khanna. Understanding Organizational Behaviour. New Delhi: Oxford University Press; 2011
4 Luft, Joseph. On Human Interaction. New York: Mayfield Pub Co;1973

5 WHO, Regional Office for South East Asia, Leadership and Strategic Management for TB Control Mangers, Personal Effectiveness Module, 2008

6 Derlega,V.J., \& Grzelak, J . Self-disclosure. Origins, patterns, and implications of openness in interpersonal relationships. San Franscisco: Jossey-Bass1976;151-76.

7 Greene, K., Derlega,V.J., Yep, G.A., Petronio, S. Privacy and disclosure of HIV in interpersonal relationships: A sourcebook for researchers and practitioners. Mahwah, NJ: Erlbaum 2003. 